NUREG/CR-0616

SAND78-0671

RS

\title{
A Network Modeling and Analysis Technique for the Evaluation of Nuclear Safeguards Effectiveness
}

Floyd H. Grant III, Robin J. Miner Pritsker \& Associates, Inc.

Dennis Engi

Sandia Laboratories

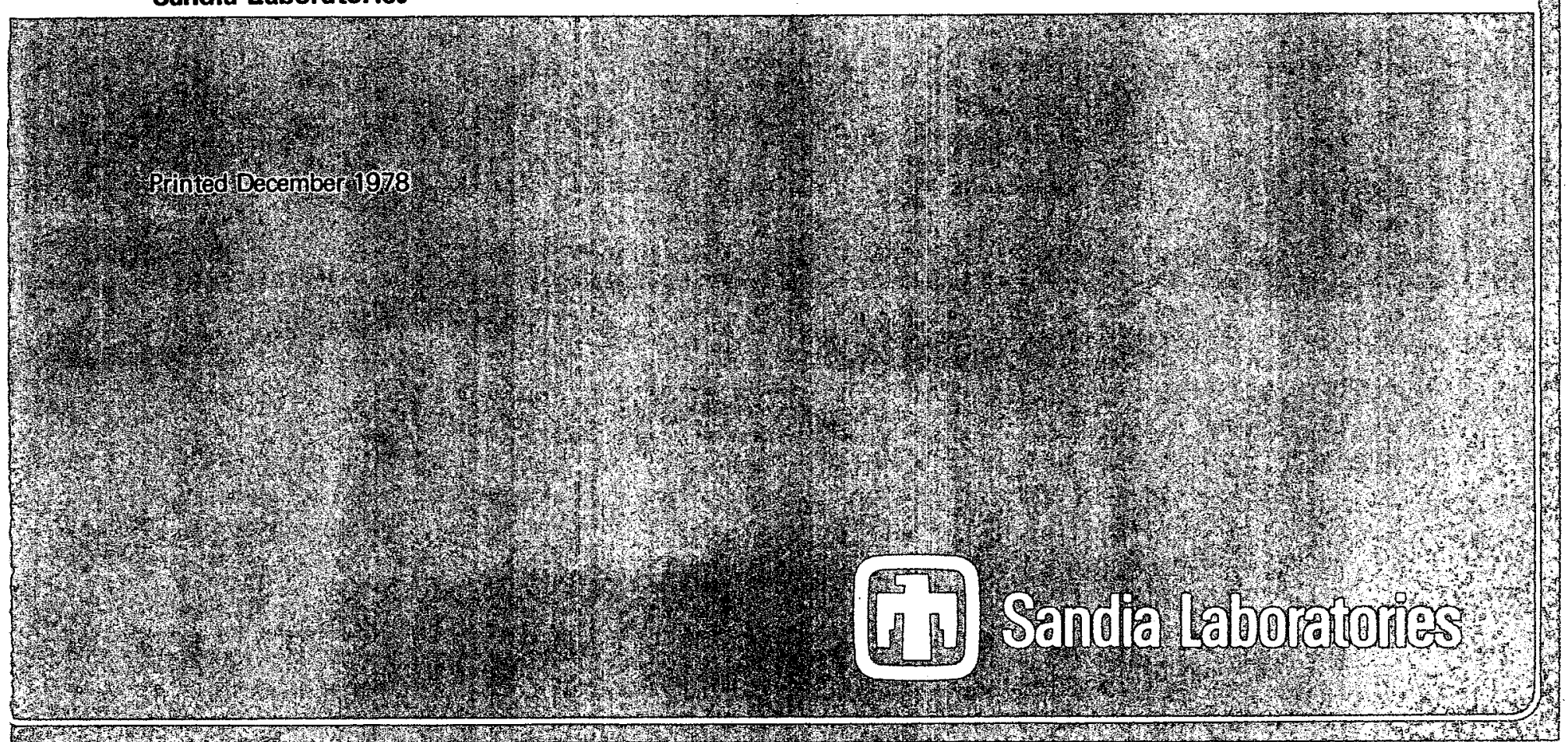

$10000(7.73)$

Prepared for

U. S. NUCLEAR REGULATORY COMMISSION 


\section{DISCLAIMER}

This report was prepared as an account of work sponsored by an agency of the United States Government. Neither the United States Government nor any agency Thereof, nor any of their employees, makes any warranty, express or implied, or assumes any legal liability or responsibility for the accuracy, completeness, or usefulness of any information, apparatus, product, or process disclosed, or represents that its use would not infringe privately owned rights. Reference herein to any specific commercial product, process, or service by trade name, trademark, manufacturer, or otherwise does not necessarily constitute or imply its endorsement, recommendation, or favoring by the United States Government or any agency thereof. The views and opinions of authors expressed herein do not necessarily state or reflect those of the United States Government or any agency thereof. 


\section{DISCLAIMER}

Portions of this document may be illegible in electronic image products. Images are produced from the best available original document. 

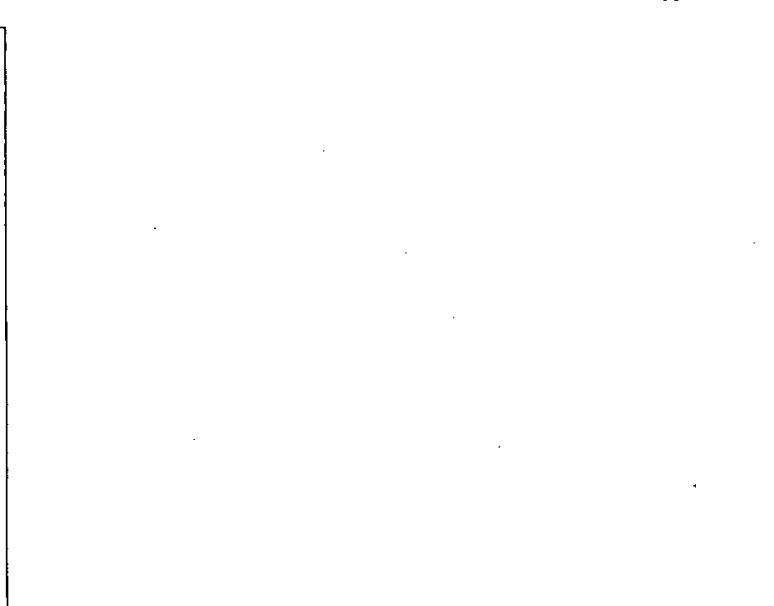

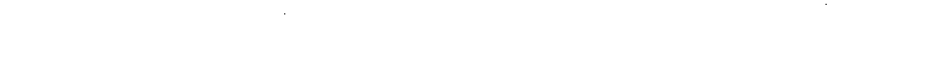
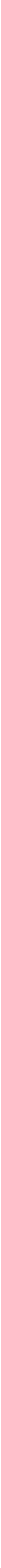
. . 


\title{
NUREG/CR-0616 \\ SAND78-0671 \\ RS
}

\author{
A NETWORK MODELING AND ANALYSIS TECHNIQUE FOR THE \\ EVALUATION OF NUCLEAR SAFEGUARDS SYSTEMS EFFECTIVENESS \\ Floyd H. Grant III and Robin J. Miner \\ Pritsker \& Associates, Inc. \\ West Lafayette, IN 47906 \\ Dennis Engi \\ Safeguards Methodology Development Division \\ Sandia Laboratories \\ Albuquerque, NM 87185
}

Date Published: February 1979

Sandia Laboratories

Albuquerque, New Mexico 87185 operated by

Sandia Corporation for the

U.S. Department of Energy
This report was prepaTICE

sponsored by was prepared as an account of work United Siates nor the United Sovemment. Neither the Enetgy, nor any of their emplates Depastment of contractors, subcon their employees, nor any of their any wartanty, express or ins, or their employees, makes liability or responsial or hinplied, or assumes any legal

or usefulness of any inf for the accuracy, completeness

process disclosed, or information, apparatus, product or infringe privately owned rists that its use would not

Prepared for

Division of Safeguards, Fuel Cycle and Environmental Research Office of Nuclear Regulatory Research

U.S. Nuclear Regulatory Commission

Washington, D.C. 20555

Under Interagency Agreement DOE 40-550-75

NRC FIN No. A1060 


\section{ABSTRACT}

Nuclear safeguards systems are concerned with the physical protection and control of nuclear materials. The Safeguards Network Analysis Procedure (SNAP) provides a convenient and standard analysis methodology for the evaluation of safeguards system effectiveness. This is achieved through a standard set of symbols which characterize the various elements of safeguards systems and an analysis program to execute simulation models built using the SNAP symbology. The reports provided by the SNAP simulation program enable analysts to evaluate existing sites as well as alternative design possibilities. This paper describes the SNAP modeling technique and provides an example illustrating its use. 


\section{CONTENTS}

Page

Introduction

Modeling Philosophy

SNAP Symbology

SNAP Application

Conclusion

Bibliography

\section{ILLUSTRATIONS}

\section{$\underline{\text { Figure }}$}

1 Safeguard Systems Model

2 Exemplary Facility Schematic

3 SNAP Model of the Exemplary Facility

4 Guard Force Scenario Network

15

5 Adversary Force Scenario Network

17

6 Simulation Trace Excerpt

TABLES

\section{Table}

I Facility Model Symbology

II Guard and Adversary Model Symbology

III Performance Measures 


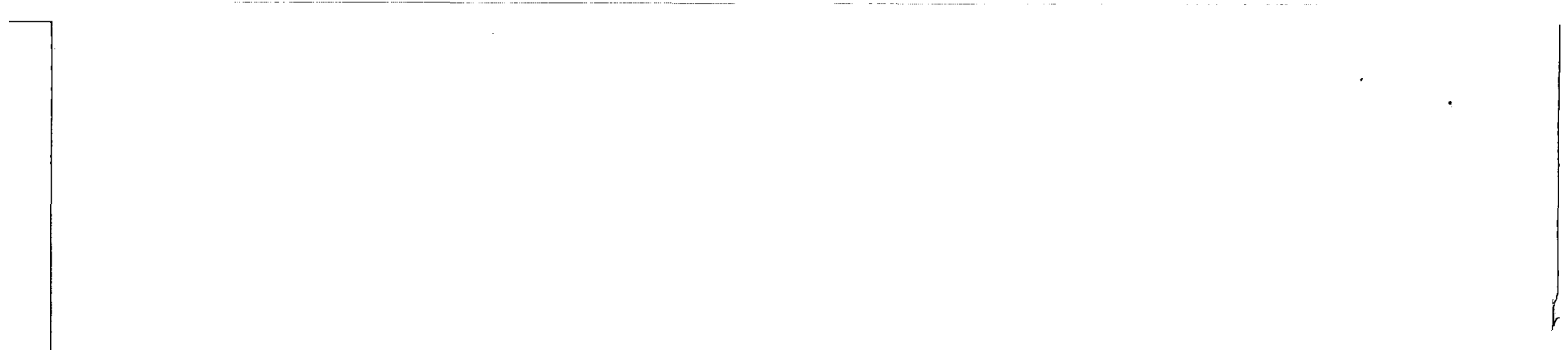




\begin{abstract}
A NETWORK MODELING AND ANALYSIS TECHNIQUE FOR THE EVALUATION OF NUCLEAR SAFEGUARDS SYSTEMS EFFECTIVENESS*
\end{abstract}

\title{
Introduction
}

Safeguards systems are concerned with the protection and control of nuclear materials. The existence of these safeguards systems is motivated by the possibility of loss of nuclear material due to unreliable equipment and procedures or due to sabotage and theft. This research is concerned with those systems which are designed to protect nuclear material at a fixed site. The primary objective is to provide a means of. evaluating the resistance of the system to sabotage or theft. Examples of safeguards systems include nuclear reactor sites, spent fuel storage sites, and fuel fabrication facilities.

The Safeguards Network Analysis Procedure (SNAP) developed through this research fulfills this objective. SNAP employs the network modeling approach to problem solving. By combining the SNAP symbology with knowledge of the system, specific scenarios, and modeling objectives, a network model of the system may be developed. Standardized procedures have been defined for describing the model in a data form acceptable to a computer program. The SNAP analysis program is used to simulate the system of interest. Reports are generated by the program to provide information which allows the analyst to evaluate the performance of proposed or existing safeguards systems.

Models of fixed-site, nuclear facility, physical protection systems were under development as early as 1974. The need for such models is essentially two-fold: they offer a consistent approach to the objective evaluation of the effectiveness of a physical protection system in defending against some hypothesized adversary, and they provide a quantitative technique for upgrading extant facilities and designing new facilities.

Experience gained from the early modeling attempts provided the impetus for the development of SNAP. Methodological completeness was a

\footnotetext{
${ }^{*}$ Presented at the 1978 Winter Simulation Conference, December 4-6, Miami Beach, Florida. Sponsored by The Society for Computer Simulation (Simulation Councils, Inc.).
} 
primary issue in the conceptualization of SNAP. This completeness has been argued for and interpreted in two quite distinct ways--producing the dichotomy macro- vs. micro-completeness. A safeguards methodology can be termed macro-complete if it can feasibly be used to evaluate effectiveness for all reasonable adversary scenarios. Alternatively, a micro-complete methodology is one in which safeguards effectiveness is evaluated for each individual scenario in sufficient detail to adequately represent all relevant considerations. In SNAP the intent is to treat both micro- and macro-completeness with the same level of emphasis.

In satisfying the implied Janus-faced completeness constraint, SNAP is conceptually appealing to the safeguards evaluator who has no previous experience with the use of models as well as to the professional modeler. This appeal is a result of the standard set of "safeguards symbols" which SNAP employs to characterize the various elements of the safeguards systems. These symbols enable the analyst to represent complex scenarios with a modest amount of effort. Once constructed, these symbolic representations translate directly into data for the SNAP computer program which, in turn, yields estimates for a variety of safeguards effectiveness measures.

\section{Modeling Philosophy}

The modeling philosophy of SNAP may be defined on two levels. On the general level, SNAP employs the network modeling approach to problem solving. On the specific level, SNAP provides a structure for safeguards systems analysis by dividing safeguards systems into three interacting submodels. These two levels of approach will be discussed in detail.

In using the network modeling approach to problem solving, a network symbology, system knowledge, specific scenarios, and modeling objectives are combined to form a network model of the system. Data describing the model and the SNAP Analysis Program are used in conjunction with a computer to produce reports that provide information to evaluate the performance of the safeguards system. One of the basic advantages of network simulation is that it frees the analyst from the programming task. Network modeling provides analysts with a communication and documentation vehicle as well. 
In developing models of various safeguards systems, certain submodel elements are common to every situation. These various submodels interact with each other to produce the overall behavior of the system. This interaction is illustrated in Figure 1.

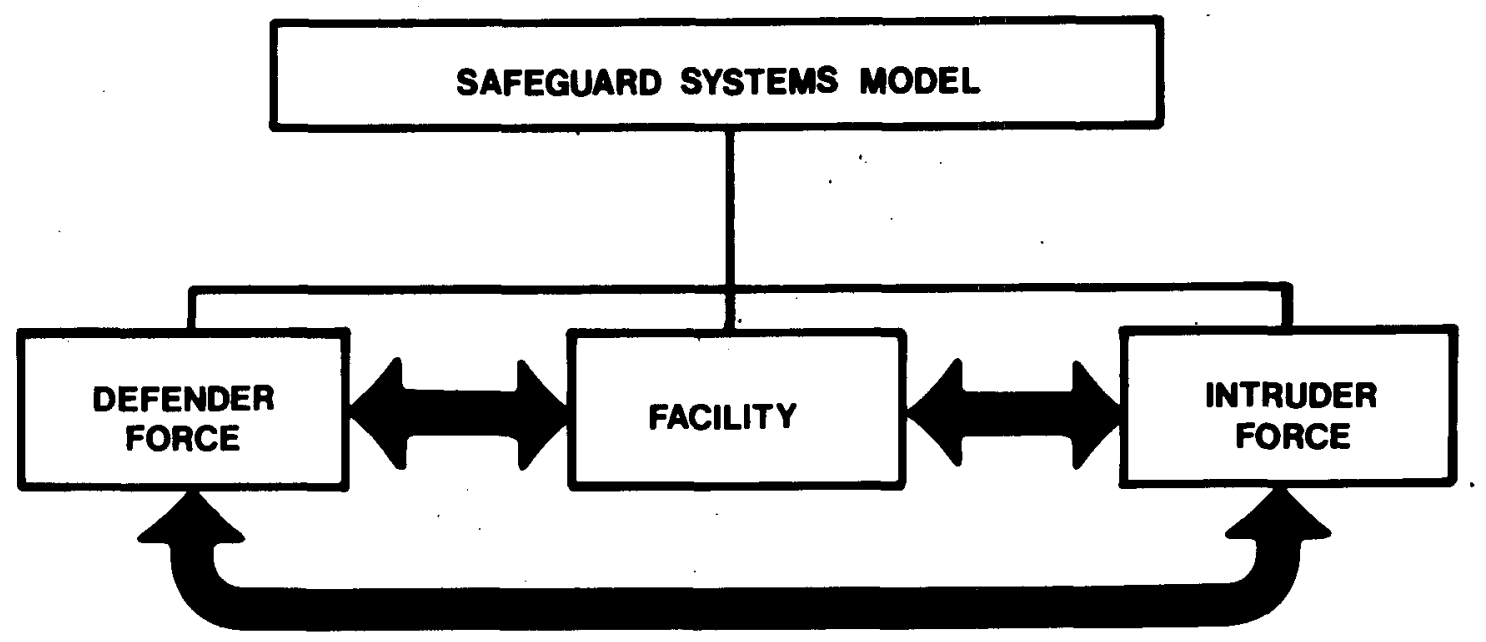

Figure 1. Safeguard Systems Mode1

The most fundamental submodel is concerned with the physical characteristics of the facility itself. In SNAP, this model is a static model, i.e., transactions do not flow through it. The facility model defines various components of the safeguards facility and their relationships.

A second submodel involves guard operating policies. The guard submodel includes a representation of the decision logic associated with guard forces as well as the physical movement of guards through the facility. Guards may make decisions based on system status information as they progress through the network.

A similar model of the adversary process is included. The decision logic and sequence of events which an adversary must complete to reach a certain target are represented in this submodel. Adversary forces also make decisions based on system status information.

The three submodels of the system have numerous points of interaction. The guard submodel interacts with the facility model through sensor detection, actual movement through the facility, etc. The adversary submodel interacts with the facility in a similar manner. 
Interaction is also necessary between the guard submodel and the adversary submodel. This is accomplished in two ways. First, each group has some knowledge about the capabilities of the opposing force. A set of attributes which define one group's knowledge of the other are maintained for this purpose. As in the real system, the attributes contain information obtained only at the time of detection and it may or may not be current. These attributes are updated as guards and adversaries flow through their respective submodels. Decisions may be made based upon these attributes.

The second level of interaction between the two forces is the engagement. The model of the engagement is probabilistic in nature and is based on the characteristics of the forces involved. Future force movements and decisions may be made depending upon whether a force wins or loses the engagement. This engagement model is a Monte-Carlo version of BATLE (Brief Adversary-Threat Loss-Estimator), an analytic model developed at Sandia Laboratories.*

In summary, SNAP provides analysts with a network modeling approach for the simulation and analysis of safeguards systems. Safeguards models are built by defining three subsystem models representing the facility, the guard force, and the adversary force. Guard and adversary forces interact with the facility model through their movement within that facility. They interact with each other through sensor detections and engagements. The next section will discuss the elements of the SNAP symbology.

\section{SNAP Symbology}

The SNAP symbology is designed to form a one-to-one correspondence with the actual physical components and guard or adversary actions. That is, there is a set of symbols for modeling the facility of interest and for developing models of the adversary and guard force scenarios as they relate to that facility.

The procedure for modeling safeguards systems using the SNAP symbology is as follows:

\footnotetext{
${ }^{*}$ D. Engi and J. S. Shanker, "Brief Adversary-Threat Loss-Estimator (BATLE) User's Guide," SAND78-1136, Sandia Laboratories, Albuquerque, New Mexico, to be published.
} 
The analyst first builds the model for the facility

that he wishes to study using the facility model

symbology. Then, using the guard and adversary

model symbologies, he constructs various scenarios.

These scenarios, "with the facility model, are

simulated and information is generated to provide

relative measures of system performance. Through

this procedure, the analyst may evaluate various

defender policies and facility design alternatives.

The SNAP symbology for the facility model is shown in Table I. The PORTAL, SPACE, BARRIER, and TARGET elements identify actual facility system components. Adjacency and Precedence branches define their interrelationships. Adversary Detection Devices (ADD) include sensors and monitors. The user identifies SNAP elements by alphanumeric labels. For example, the user specifies that a sensor label is associated with a certain node by entering the label for that sensor in the appropriate portion of the node (indicated by ADD in Table I).

\section{TABLE I}

Facility Model Symbology

PORTAL

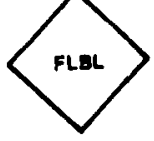

SPACE

$\cdot$

(1)

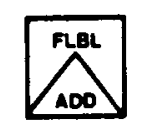

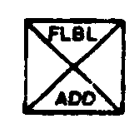

TARGET

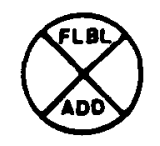

ADD

data card
System Entrance Point

Space in Facility

Barrier in Facility

Adversary Objective

Adversary Detection Devices

Adjacency

and

Precedence 
Based on the model of the facility of interest, the user then builds models of the guard and adversary scenarios to be considered. These models are built using the guard and adversary symbology shown in Table II. Each of these elements will relate directly to a particular activity of the force being modeled. For example, the process of an adversary crossing a fence is modeled using a TASK node. This node is tied directly to the facility model node which represents the fence by its alphanumeric label, as indicated by FLBL on the TASK node. Similar procedures hold for the other nodes.

TABLE II

Guard and, Adversary Model Symbology

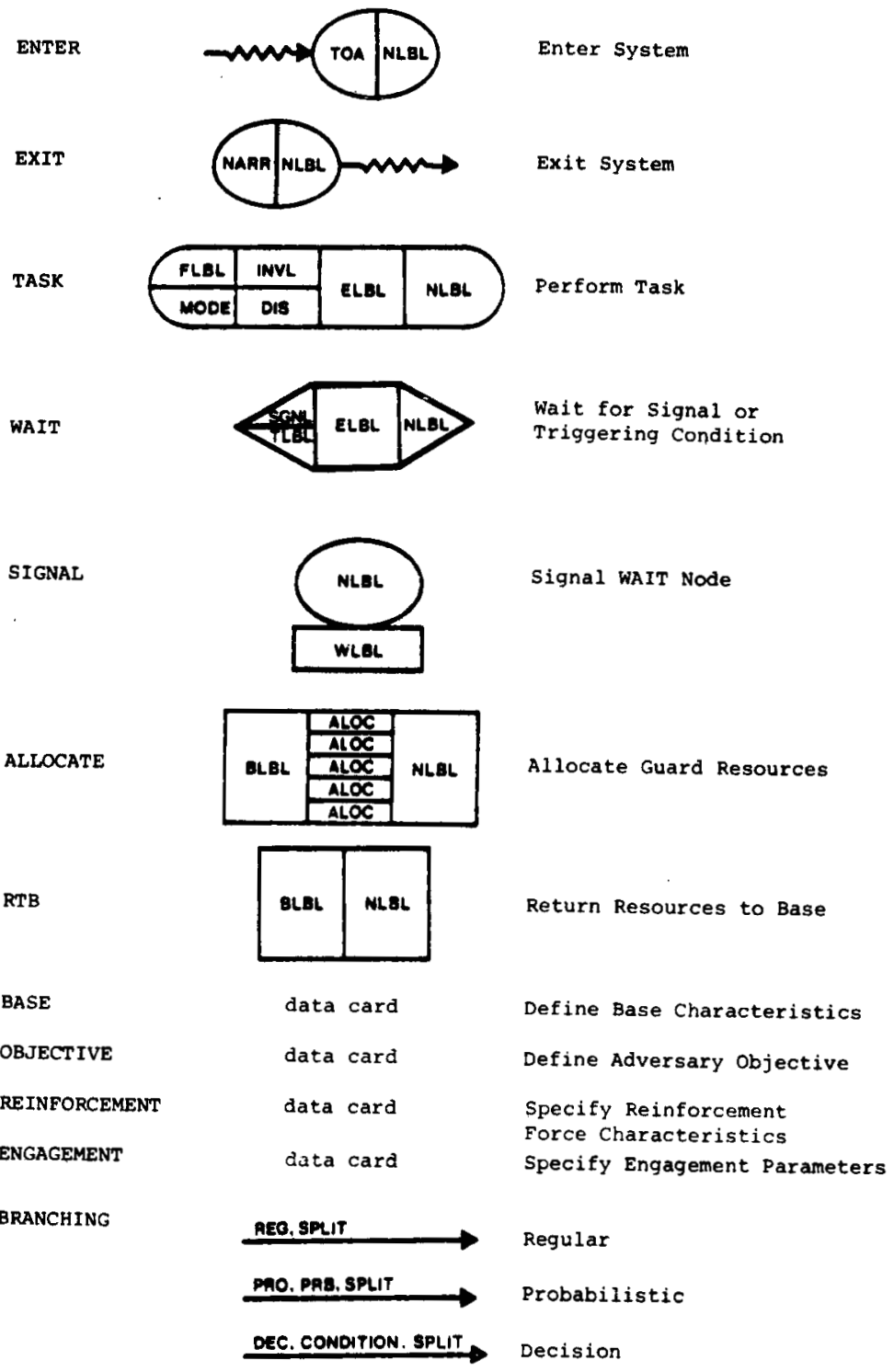


A unique data card has been defined for each element in the three models. Information specified on the user's network is transferred directly to these data cards, which are processed by the analysis program. The simulation of the model is then executed by running the SNAP analysis program and output reports are automatically generated.

In order to illustrate the use of the symbology and indicate the analysis information available, the following example application is provided.

\section{SNAP Application}

This application illustrates the use of SNAP concepts and symbols to model systems concerned with protecting nuclear material from sabotage or theft.

A diagram of the exemplary nuclear storage facility to be used for this application is shown in Figure 2. A fence surrounds the

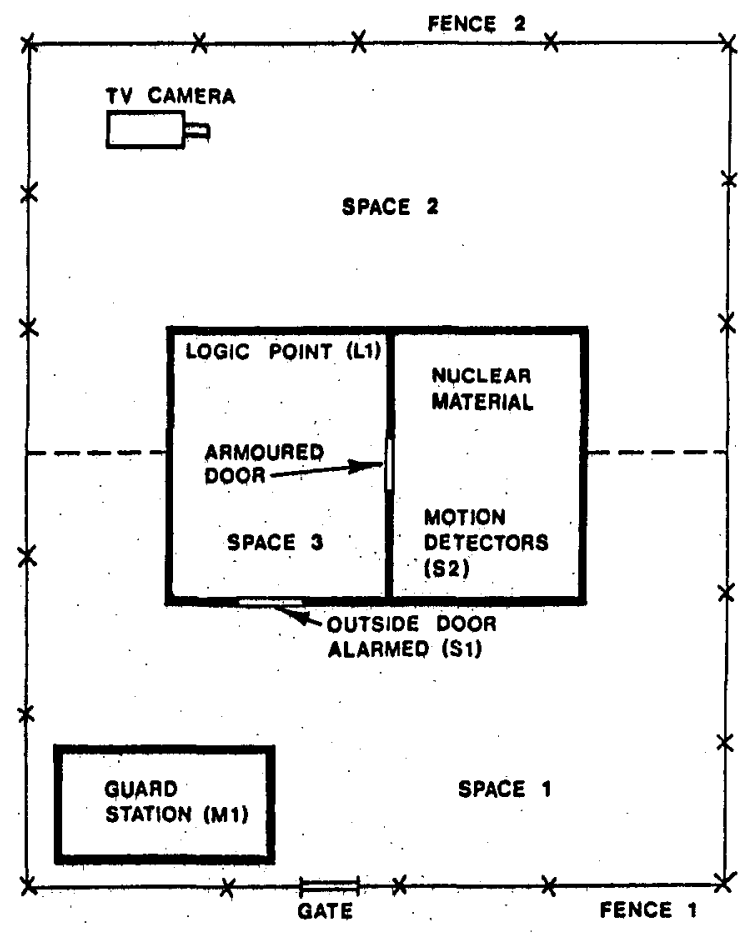

Figure 2. Exemplary Facility Schematic 
storage building on all sides. For modeling purposes, the fence has been divided into two parts, fence 1 and fence 2 . The space surrounding the storage building has also been divided into two parts, space 1 and space 2. There is a TV camera in space 2 monitoring that space. The TV camera functions as a sensor and will be referenced as sensor S3. A guard station which monitors all sensors on the site is located in space 1. The outside door is alarmed and may be entered from space 1. Space 3 contains the logic point LI through which the signals from sensors S1, S2, and S3 must pass before reaching the monitor (M1) at the guard station. Disablement of logic point Ll, would interrupt the flow of information from those sensors to the guard station monitor. An armoured door separates space 3 and the target, the nuclear material. The nuclear material is monitored by sensor $\$ 2$, a motion detector.

Figure 3 presents the corresponding SNAP facility subnetwork. This figure has been labeled so as to make a correspondence between the

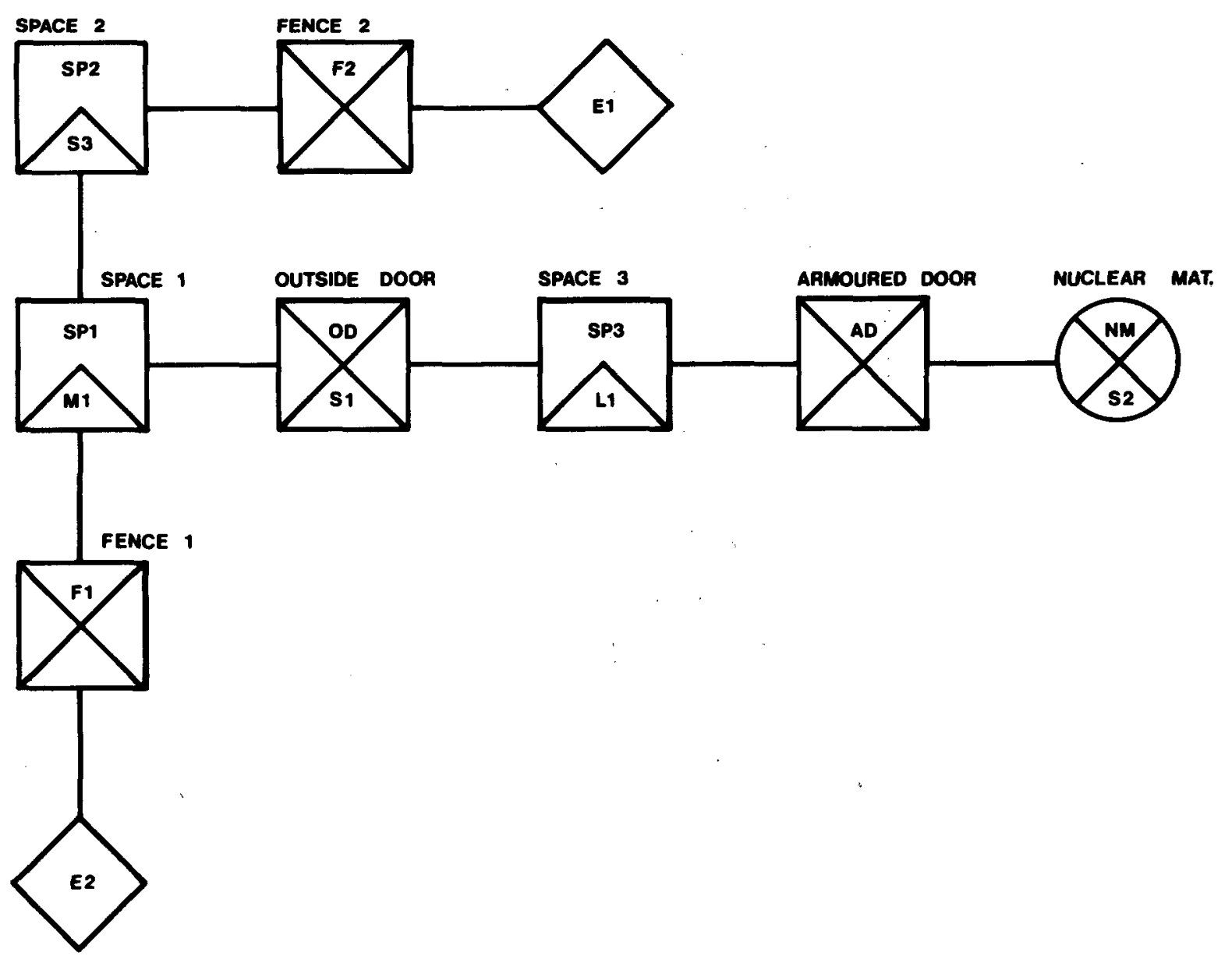

Figure 3. SNAP Model of the Exemplary Facility 
storage site schematic and the model readily apparent. Note that there are two possible entrances by adversaries denoted by portal nodes El and E2. These are connected to two barrier nodes which represent fence 1 and fence 2. Paths that the adversary might take are easily determined for this model. Since adversary and guard forces may travel in either direction between the various facility components, only adjacency is indicated on the branches between the nodes in this model.

After the facility model is developed, the adversary and guard subnetworks are built in reference to that facility model.

The guard force subnetwork is shown in Figure 4. The guard force transaction enters (ENT) the guard subnetwork at time 0.0 and begins monitoring the three sensors ( $W 1$, $W 2$, and $W 3$ ).

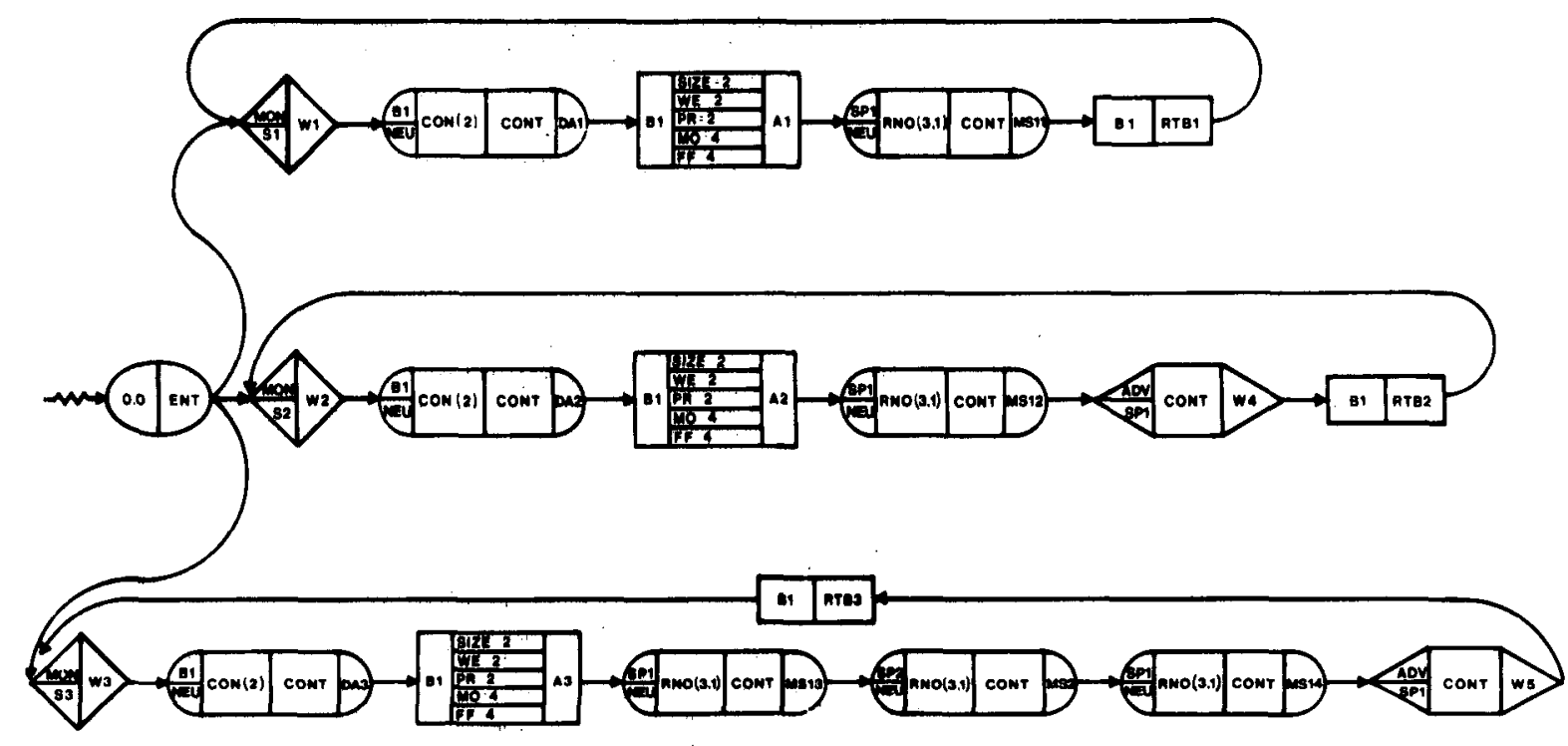

Figure 4. Guard Force Scenario Network

Sensor Sl is the sensor on the alarmed outside door. If sensor $S I$ is triggered the guard force takes two minutes to muster forces (DAl). A force of two members is allocated (Al) from base Bl. The guard force then moves (MSII) into space 1 to assess the situation. If no adversaries are detected during the time the guards are on patrol, the guard force returns to base (RTBI) and resumes the monitoring of sensor SI. If adversaries are encountered, an engagement will ensue. 
Sensor S2 represents the motion detector in the material access area. If sensor $\mathrm{S} 2$ is triggered, the guard force takes two minutes to muster forces (DA2). A force consisting of two members is then allocated (A2) from base B1. This force is the same force that is allocated if sensor $\mathrm{Sl}$ is triggered. The guard force then moves (MS12) into space 1 to search for adversaries. If adversaries are encountered, an engagement will ensue. If no adversaries are found, the guard force will wait (W4) at space 1 for an adversary force to arrive. If adversaries do arrive, an engagement will ensue. If the guards win, they return to base (RTB2) and begin monitoring sensors again.

Sensor $\mathrm{S} 3$ is the $\mathrm{TV}$ camera.' If sensor $\mathrm{S3}$ detects adversaries in space 2, the guard force musters (DA3) and allocates (A3) two guards from base Bl. The force then enters space 1 (MSI3) to search for adversaries. If none are found, the guard force moves into space 2 (MS2), continuing the search. After space 2 has been searched and if no adversaries have been found, the guards return to space 1 (MS14) to search again. If the guard force encounters an adversary force at any time during the searching of space 1 or space 2, an engagement will occur. If the guards win the engagement, they continue their search procedures to locate any other adversaries which may be present. After searching for adversaries in space 1 and space 2 , the guards wait (W5) in space 1 for further instructions. If the guards encounter an adversary while they are waiting, an engagement will begin. If the guards win the engagement, they return to base (RTB3) and begin monitoring sensors again.

This summarizes the operating policies which the guards will follow in this model. This guard model is typical of guard responses to adversary intrusion for the hypothetical facility under consideration.

The adversary force subnetwork is shown in Figure 5. The adversary's objective is to achieve a radiological release through sabotage of the nuclear material in space NM by using an explosive device. The adversaries enter (ENTI) at time 0.0 and immediately penetrate fence 1 (CFI). Next, they cross space 1 (CSP1) and divide their force in half. Half of the force moves into space 2 (CSP2) as a diversion. They wait in space 2 until the other half of their force joins them. The other half begins penetration of the alarmed outside door. Fifty percent of the time they will disable sensor $S 1$ and not be detected (DOD or DODN). After penetrating the outside doors, this adversary force crosses 


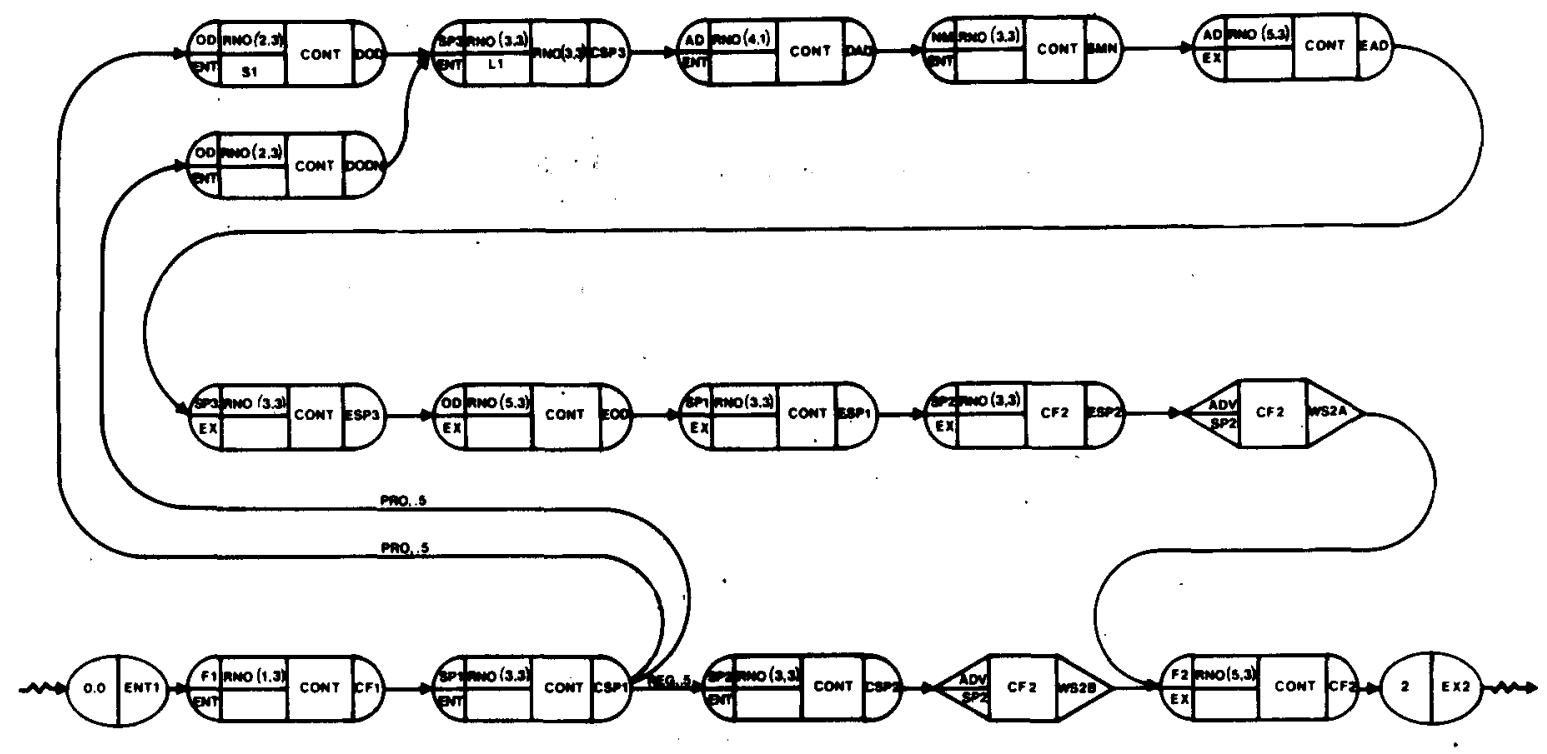

Figure 5. Adversary Force Scenario Network

space 3 (CSP3) and penetrates the armoured door (DAD). They then sabotage the nuclear material (SMN) by leaving an explosive device and retrace their steps through the armoured door (EAD), across space 3 (ESP3) and through the outside door (EOD), and into space 1 (ESP1). They cross space 1 and move into space 2 (ESP2) where they join with the other adversary force (WS2A). When both adversary forces are in space 2, they join and penetrate fence 2 (CF2), exiting the facility (EX2). Since the adversary objective is sabotage, the adversaries do not have to exit the network to be successful.

Figure 6 shows a portion of the trace generated from a simulation run of this model. The guard force enters and begins monitoring the sensors. From this trace, an event-by-event account of one realization of the network can be obtained. The information on this trace relates directly to the networks defined by the user.

This model was simulated 500 times to generate statistics. The results of these simulations are shown in Table III. From these results, the user can obtain information concerning the behavior of the existing system. The overall performance measure, the probability the adversary achieves his objective, was observed to be 0.13 . That is, in this example, the adversary can sabotage the nuclear material 13 percent of the time. This would most likely be viewed as an unacceptable level of performance and indicate that revisions to the facility or guard operating 


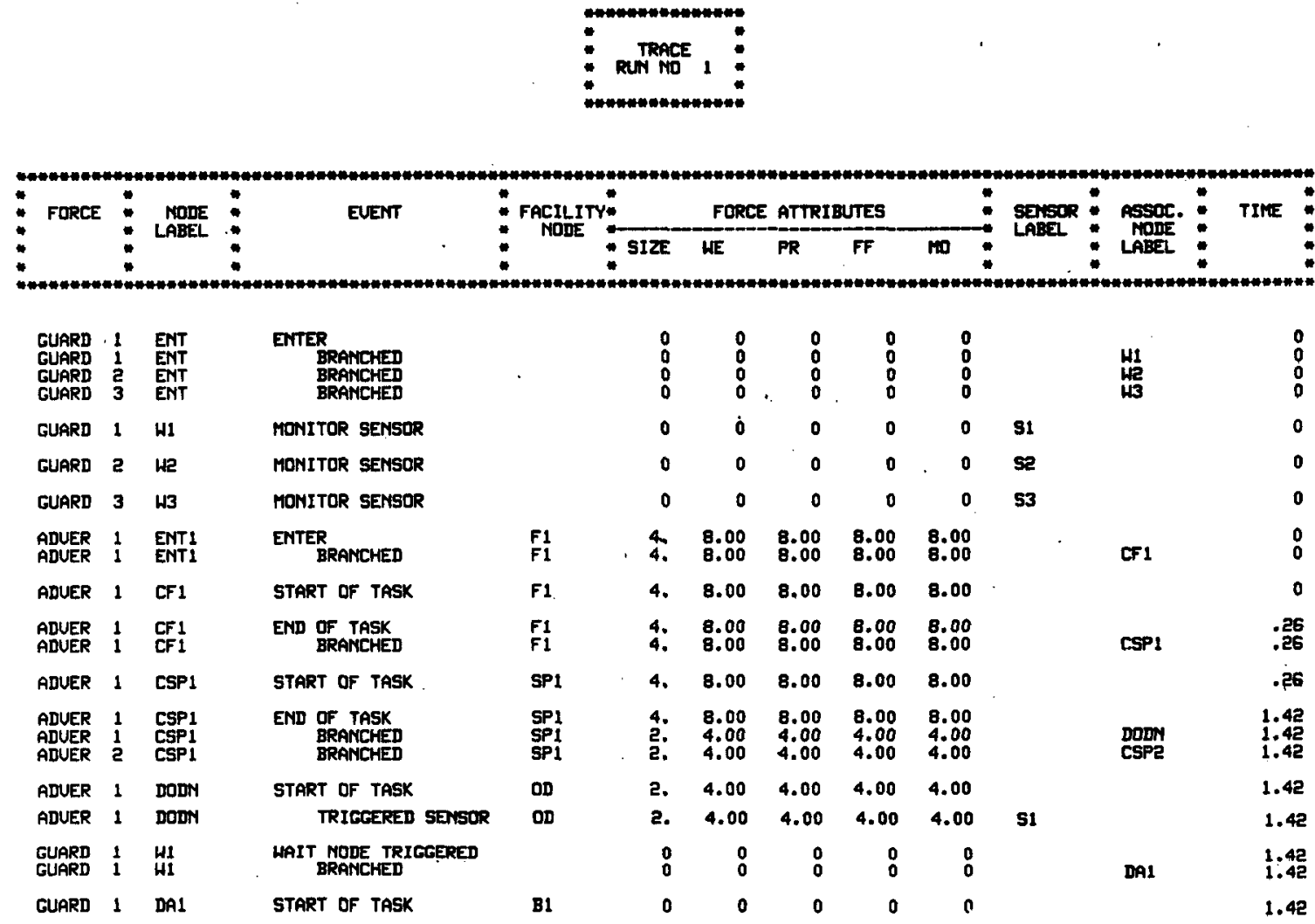

Figure 6. Simulation Trace Excerpt

policies are warranted. More specific performance measures are available as indicated.

TABLE III

Performance Measures

Average Number of Engagements Per Run

Average Number of Engagements Won by Guards Per Run

1.42

Average Number of Engagements Won by Adversaries

Per Run

Probability Adversary Achieves Objective

0.55

Number of Guard Casualties Per Run

0.13

Number of Adversary Casualties Per Run

2.42

Time for Engagement

Total Engagement Time Per Run

3.00

Number of Engagements Per Run

$5.51 \mathrm{~min}$.

$10.87 \mathrm{~min}$.

Time Between Adversary Entrance and First

1.97

Engagement

Scenario Simulation Time

Scenario Simulation Time Given Adversary Succeeds

$3.29 \mathrm{~min}$. Scenario Simulation Time Given Adversary Fails

$16.21 \mathrm{~min}$.

$39.43 \mathrm{~min}$.

12.58 min. 


\section{Conclusion}

The major objective in the development of SNAP was to build a network simulation technique specifically"tailored for the modeling and analysis of safeguards systems. Using the SNAP symbology, models of safeguards systems are built in three interactive submodels. Through the application of data input procedures, the SNAP analysis program simulates the network model developed and provides sumnary reports concerning the behavior of the system. Thus, SNAP provides analysts with a tool for evaluating alternate safeguards systems designs and refining safeguards procedures at existing sites. 


\section{Bibliography}

Bach, R. E., Jr., L. Dolansky, and H. L. Stubbs. "Some Recent Contributions to the Lanchester Theory of Combat." Opns. Res., 10 (1962), 314-326.

Boozer, D. D. and D. Engi. Insider Safeguards Effectiveness Model (ISEM) Users Guide. SAND77-0043, Sandia Laboratories, Albuquerque, New Mexico, November 1977.

Brackney, H. "The Dynamics of Military Combat." Opns. Res., 7 (1959), $30-44$.

Chapman, L. D., G. A. Kinemond, and D. W. Sasser, Users Guide for Evaluating Alternative Fixed-Site Physical. Protection Systems Using "FESEM". SAND77-1367, Sandia Laboratories, Albuquerque, New Mexico, November 1977.

Deitchman, S. J. "A Lanchester Model of Guerrilla Warfare." Opns. Res., $10(1962), 818-827$.

Engel, J. H. "A Verification of Lanchester's Law." Opns. Res., 2 . (1954), 163-171.

Engi, D. A Small-Scale Engagement Model with Arrivals: Analytical Solutions. SAND77-0054, Sandia Laboratories, Albuquerque, New Mexico, April 1977.

Engi, D. and J. S. Shanken, "Brief Adversary-Threat Loss-Estimator (BATLE) User's Guide." SAND78-1136, Sandia Laboratories, Albuquerque, New Mexico, to be published.

Grant, F. H. and R. J. Miner, Safeguards Network Analysis Procedure, Final Report. Pritsker \& Associates, Inc.: West Lafayette; Indiana, May 1978 .

Lanchester, F. W. Aircraft in Warfare: The Dawn of the Fourth Arm. London: Constable, 1916.

Morse, P. M. and G. E. Kimball, Methods of Operations Research. New York: John Wiley and Sons, 1951.

Pritsker, A. A. B. The GASP IV Simulation Language. New York: John Wiley and Sons, 1974 .

Schaffer, M. M. "Lanchester Models of Guerrilla Engagements." Opns. Res., 16 (1968), 457-488.

Weiss, H. K. "Lanchester-Type Models of Warfare," Proc. First Interr national Conf. on Operational Res., Oxford, September 1977. 


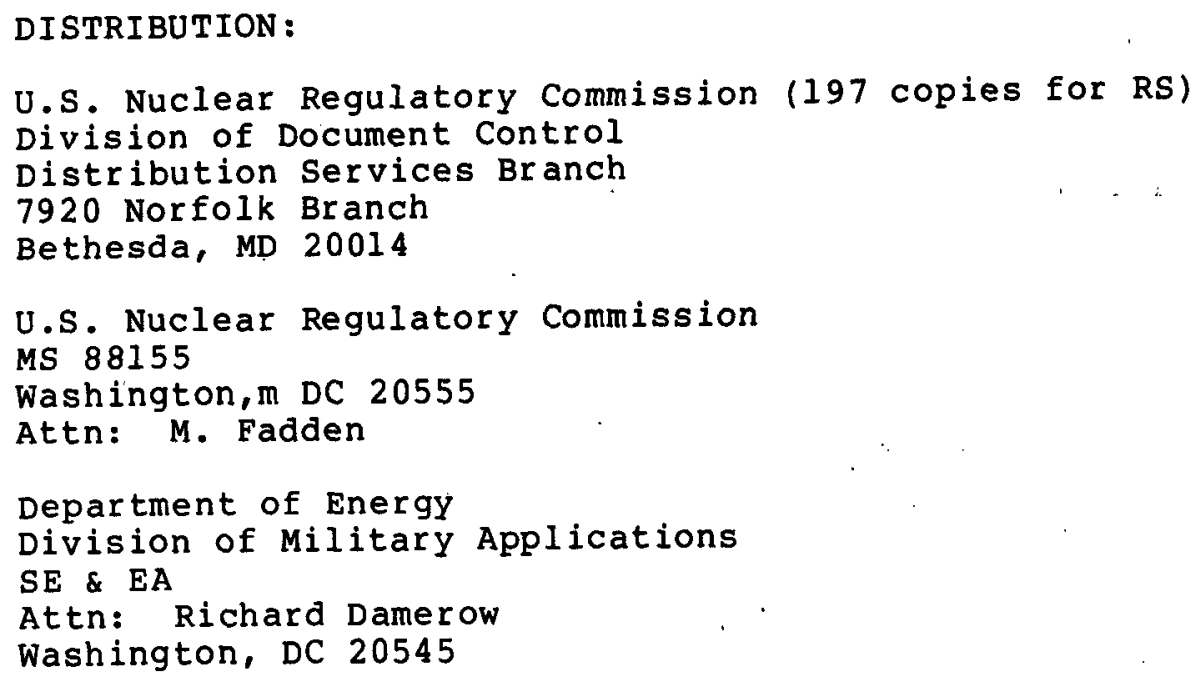

1213 V. E. Gibbs

1230 W. L. Stevens, Attn: R. E. Smith, 1233

1310 A. A. Lieber, Attn: W.F. Roherty, 1311

1700 W. C. Myre

1710 V. E. Blake, Attn: M. R. Madsen, J. W. Kane

1716 R. L. Wilde, Attn: B. D. Link, 1716

1730 C. H. Mauney, Attn: J. D. Williams, D. L. Mangan

1750 J. E. Stiegler

1754 J. F. Ney, Attn: J. L. Todd, 1754

1758 C. E. Olson, Attn: D. D. Boozer; G. A. Kinemond, 1758

1760 J. Jacobs, Attn: M. N. Cravens, J. M. deMontmoli in, 1760A

1761 T. A. Sellers, Attn: A. E. Winblad, J. L. Darby, 1761

1762 H. E. Hansen 
DISTRIBUTION： (Continued)

1765

4400

4410

4413

4414

4414

4414

4414

4414

4416

4416

4416

4416

4416

4416

4416

4416

4416

4416

4416

4416

4416

4416

5000

5640

3141

3151

3172-3 R. P. Campbell (25)

D. S. Miyoshi

A. W. Snyder

D. J. McCloskey

N. R. Ortiz

D. E. Bennett

S. L. Daniel

M. S. Hill

R. B. Jones

G. B. Varnado

L. D. Chapman

K. G. Adams

J. A. Al lensworth

H. A. Bennett

D. Engi

L. M. Grady

C. P. Harlan

C. M. Hart

R. D. Jones

M. T. Olascoaga

C. J. Pavlakos

D. W. Sasser

D. R. Strip

A. A. Trujillo

J. K. Galt

G. J. Simmons, Attn: B. L. Hulme, L. F. Shampine, 5642

T. L. Werner (5)

W. L. Garner (3)

For: DOE/TIC (Unlimited Release)

For NRC Distribution to NTIS 